\title{
Sintering Behavior and Mechanical Properties of Biphasic Calcium Phosphate Ceramics
}

\author{
Mehmet Yetmez \\ Department of Mechanical Engineering, Bulent Ecevit University, 67100 Zonguldak, Turkey \\ Correspondence should be addressed to Mehmet Yetmez; yetmez@beun.edu.tr
}

Received 2 June 2014; Revised 7 August 2014; Accepted 12 August 2014; Published 25 August 2014

Academic Editor: Amit Bandyopadhyay

Copyright (C) 2014 Mehmet Yetmez. This is an open access article distributed under the Creative Commons Attribution License, which permits unrestricted use, distribution, and reproduction in any medium, provided the original work is properly cited.

\begin{abstract}
The sintering behavior and the mechanical properties of a mechanical mixture of hydroxyapatite and tricalcium phosphate (BCP) ceramics with the composition of $30 \% \mathrm{HA}$ and $70 \% \mathrm{TCP}$ are experimentally investigated in the temperature range between $1000^{\circ} \mathrm{C}$ and $1300^{\circ} \mathrm{C}$. The results show that consolidation, grain growth, and Vickers hardness generally increase with increasing sintering temperature up to $1200^{\circ} \mathrm{C}$. However, microstructure observation indicates that cracks are formed along the grain boundaries as well as in the bulk of the grains after sintering at $1200^{\circ} \mathrm{C}$. Moreover, the best values of compressive strength, modulus of elasticity, and toughness are achieved in the samples sintered at $1100^{\circ} \mathrm{C}$. These properties at $1100^{\circ} \mathrm{C}$ decay with sintering at $1200^{\circ} \mathrm{C}$ and increase again after sintering at $1300^{\circ} \mathrm{C}$.
\end{abstract}

\section{Introduction}

In composite bioceramics world, many researchers have focused their interest on the development of biphasic calcium phosphate $(\mathrm{BCP})$ ceramics, especially with hydroxyapatite (HA: $\left.\mathrm{Ca}_{10}\left(\mathrm{PO}_{4}\right)_{6}(\mathrm{OH})_{2}\right)$ and tricalcium phosphate (TCP: $\left.\mathrm{Ca}_{3}\left(\mathrm{PO}_{4}\right)_{2}\right)$. Different HA:TCP ratios for BCP ceramics display different bioactive and bioresorbing capacities. Generally, this difference is directly related to porosity of the BCP. In other words, sintering behavior and mechanical properties of BCP ceramics can play a crucial role for the difference with respect to porosity, as one of the major physical properties of bioceramics [1-3].

As a major part of BCP composite ceramics, TCP is a mobile phase, which means that it has an intrinsic tendency to form agglomerations with increasing sintering temperature. There are experimental findings which show that TCPcontaining samples suffer from abnormal grain growth, as observed in their microstructure. It is known that $\beta$-TCP $\rightarrow$ $\alpha$-TCP phase transformation occurs at elevated temperatures. In samples of TCP fired at high temperatures, $\alpha$-TCP has been largely recorded in X-ray diffraction analysis. Best values for compressive strength, modulus of elasticity, and toughness in cylindrical specimens of TCP sintered are determined at $1100^{\circ} \mathrm{C}$. Density of TCP is increased with increasing sintering temperature but never reached the theoretical value of $\beta$ TCP $\left(3.07 \mathrm{~g} / \mathrm{cm}^{3}\right)$ [4-8]. Some studies for BCP ceramics show that the mean thermal expansion coefficient of dense sintered HA/ $\beta$-TCP biphasic ceramics increases almost linearly with the increase in $\beta$-TCP content. Grain growth which occurs at $1200^{\circ} \mathrm{C}$ has a more important effect than the increase of TCP loading in the properties of a HA/TCP biphasic material [9-11].

Due to the fact that BCP is a mixture of HA and TCP, it may be assumed that, on one hand, the BCP is an initially homogeneous material when HA:TCP ratio approaches zero; that is, the formation nearly becomes pure TCP. On the other hand, it turns relatively to a porous material when $60 \% \geq \mathrm{HA}$. According to that interesting feature of $\mathrm{BCP}$ ceramics, an investigation of $\mathrm{BCP}$ with composition range of $0-60 \%$ HA seems to be critical. Composition of $60 \% \mathrm{HA}$ and $40 \% \mathrm{TCP}$ is generally preferred due to its appropriate bone substitution/regeneration capabilities and good mechanical properties [12]. At that point, a question arises: what is the critical HA: TCP ratio where behavior of good bone regeneration starts? In order to answer this question, partly, half of $60 \%$ HA (i.e., BCP with $30 \% \mathrm{HA}$ and $70 \% \mathrm{TCP}$ ) is worth examining where acceptable use of HA:TCP ratio might offer advantages biomechanically. 
The purpose of this study is to investigate the sintering behavior of the BCP ceramics with a complex system $(30 \%$ $\mathrm{HA}$ and $70 \%$ TCP) and to determine the influence of the composition on the mechanical properties in the temperature range between 1000 and $1300^{\circ} \mathrm{C}$.

\section{Material and Methods}

Cylindrical biphasic calcium phosphate ceramic samples (BCP) are put together by mixing dry HA and $\beta$-TCP (MERCK, Darmstadt, Germany). The catalog numbers for HA and $\beta$-TCP are Merck \#2196 and Merck \#2143, respectively. According to the British Standard BS 7253, pellets (approximately $11 \mathrm{~mm}$ in diameter and $8 \mathrm{~mm}$ in height) are prepared by using uniaxial cold pressing in hardened steel dies. Under a heating rate of $4 \mathrm{~K} / \mathrm{min}$, the pressed samples are sintered in an open atmospheric furnace at different temperatures, specifically $1000,1100,1200$, and $1300^{\circ} \mathrm{C}$, for $4 \mathrm{~h}$. For each temperature, 13 cylindrical samples of BCP with composition of $30 \% \mathrm{HA}$ and $70 \%$ TCP are produced. After sintering at $1000,1100,1200$, and $1300^{\circ} \mathrm{C}$, their diameters are $12.39 \pm 0.31,11.07 \pm 0.08,10.52 \pm 0.1$, and $10.52 \pm 0.14 \mathrm{~mm}$ and heights are $8.46 \pm 0.41,7.96 \pm 0.38,7.55 \pm 0.8$, and $7.9 \pm$ $0.45 \mathrm{~mm}$, respectively. The density of the sintered samples is determined by the Archimedes method.

The identification of the crystalline phases is done in an X-ray diffractometer (Rigaku ZSX Primus II, Japan). The microstructural analysis is carried out by a scanning electron microscope (SEM, JEOL JSM 7000F). The Vickers hardness measurements are realized with a microhardness testing machine (Shimadzu HMV-2, Japan), using $200 \mathrm{~g}$ load applied for $20 \mathrm{~s}$ (dwell time). A universal tensile testing machine (Devotrans FU 50kN, Turkey) is used for compression strength tests under a loading rate of $1 \mathrm{~mm} / \mathrm{min}$.

The experimental results are analysed with a general purpose statistical data analysis program WINKS SDA (Version 6.0.91 Professional Ed., TexaSoft, Houston, TX). In these statistical analyses, independent group $t$-test/ANOVA with comparison type Newman-Keuls and any difference at the 5\% level are considered.

\section{Results and Discussion}

The X-ray diffractograms of the sintered BCP samples, shown in Figure 1, suggest that amount of HA decreases with increasing sintering temperature. It is also noted that a weak peak of monetite is recorded at the highest sintering temperature $\left(1300^{\circ} \mathrm{C}\right)$.

In this study, it is assumed that phase transformation between $\beta$ and $\alpha$ phase takes place between $1100^{\circ} \mathrm{C}$ and $1200^{\circ} \mathrm{C}$; that is, $\beta$-TCP forms below $1180^{\circ} \mathrm{C}$ and $\alpha$-TCP between $1180^{\circ} \mathrm{C}$ and $1430^{\circ} \mathrm{C}$ [13]. This assumption is confirmed with the results of the mechanical properties reported in the following paragraphs.

The influence of sintering temperature on the microstructure of the samples is observed in the SEM images of Figure 2. The samples are poorly sintered at $1000^{\circ} \mathrm{C}$, since only necks between the ceramic grains are observed and a large porosity throughout the whole bulk of the sample

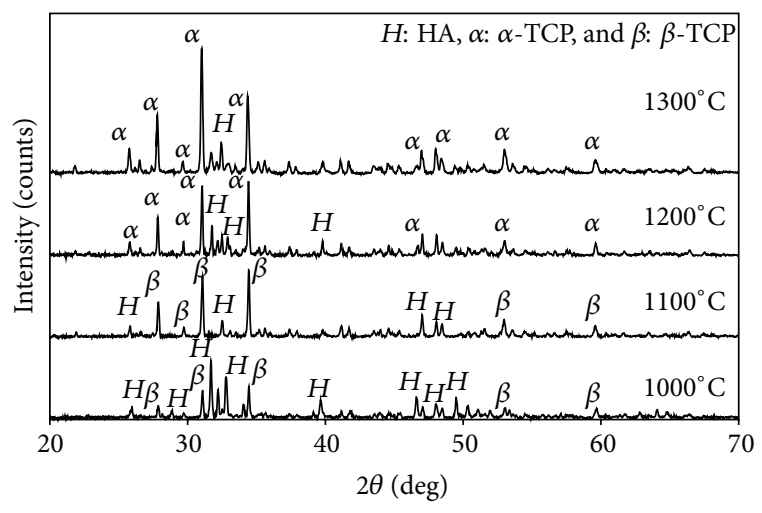

FIgURE 1: X-ray diffractograms of the BCP samples sintered at different temperatures.

TABLE 1: Mean values (with standard deviations) of density and Vickers microhardness of the BCP ceramics sintered at different temperatures.

\begin{tabular}{lcc}
\hline$T\left({ }^{\circ} \mathrm{C}\right)$ & $\rho\left(\mathrm{g} / \mathrm{cm}^{3}\right)$ & Microhardness $(\mathrm{GPa})$ \\
\hline 1000 & $1.85 \pm 0.04$ & $0.38 \pm 0.04$ \\
1100 & $2.44 \pm 0.06$ & $1.94 \pm 0.11$ \\
1200 & $2.81 \pm 0.05$ & $6.24 \pm 0.26$ \\
1300 & $2.79 \pm 0.03$ & $4.57 \pm 0.16$ \\
\hline
\end{tabular}

still exists (Figure 2(a)). Significant consolidation occurs after heat treatment at $1100^{\circ} \mathrm{C}$ (Figure 2(b)). However, small porosity still exists, whereas there is no evidence for extensive grain growth.

In Figure 2(c) extensive grain growth is observed in the samples sintered at $1200^{\circ} \mathrm{C}$. Regions with local intergranular cracks are marked with the upper black arrow. The other two (lower) black arrows mark areas with intragranular cracks with a zigzag profile. These cracks are probably activated cleavage planes located in a single grain. The fracture initiation can only be attributed to the effect of phase transformation. Apparently, these cracks, and mainly the intergranular ones, should cause a reduction of the mechanical properties of the sintered ceramics. In general, intergranular cracks grow faster than intragranular ones.

The grains pronouncedly grow at $1300^{\circ} \mathrm{C}$ (Figure $2(\mathrm{~d})$ ). At this sintering temperature, material with large grains is more fragile than material with fine-grained microstructure. In Figures 2(c) and 2(d), the variation in the contrast of the particles may be due to the rounded aspect of the particles. That is, the white dots are corresponding to the upper flat part of the particles [14].

The mean values of density and Vickers microhardness, along with the corresponding values of the standard deviations, are listed in Table 1. It is clear that the density of the BCP samples increases with increasing sintering temperature up to $1200^{\circ} \mathrm{C}$. There is actually no significant change of the densification of the samples after sintering at $1300^{\circ} \mathrm{C}$ since values of the densities at 1200 and $1300^{\circ} \mathrm{C}$ are not significantly different $(P<0.001)$. However, it is worthy to note that the measured density does not reach the theoretical value of TCP that is $3.07 \mathrm{~g} / \mathrm{cm}^{3}$ [7]. 


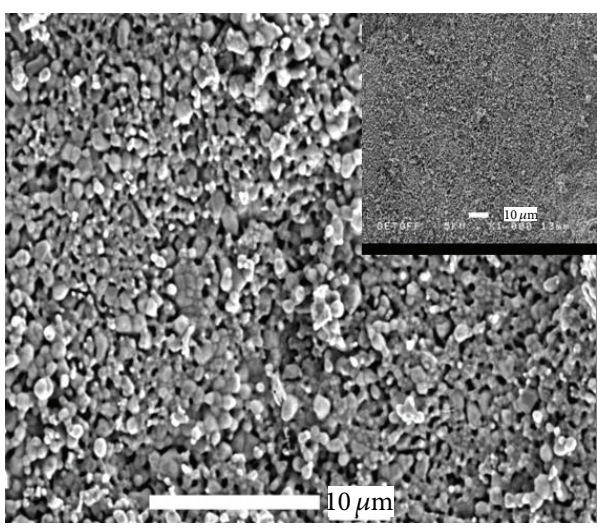

(a)

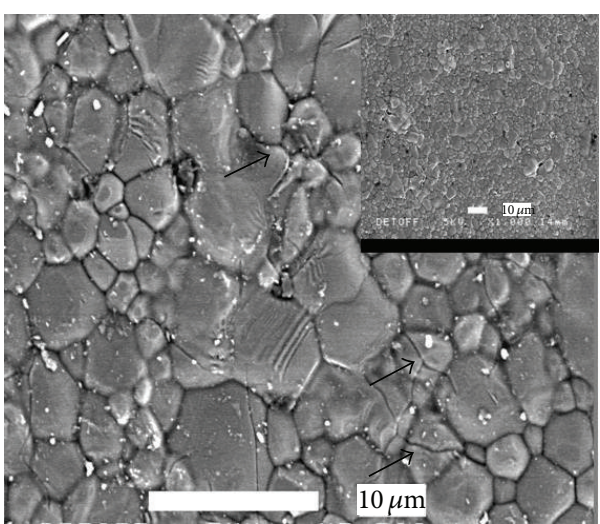

(c)

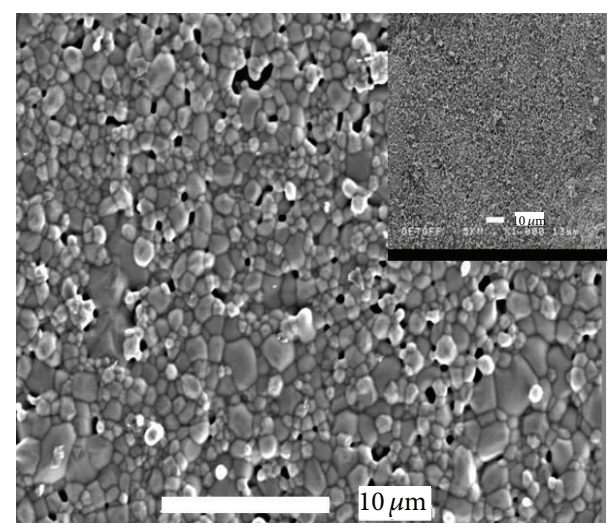

(b)

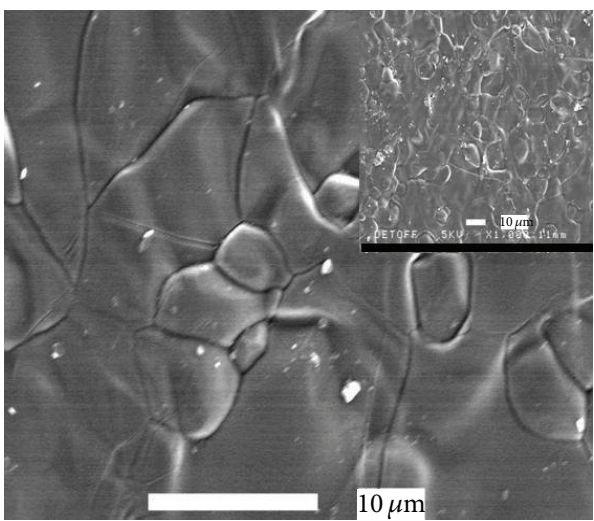

(d)

Figure 2: Microstructure of the BCP samples sintered at (a) $1000^{\circ} \mathrm{C}$, (b) $1100^{\circ} \mathrm{C}$, (c) $1200^{\circ} \mathrm{C}$, and (d) $1300^{\circ} \mathrm{C}$, observed at low ( $\times 1000$; insets) and high $(\times 3500$; main images $)$ magnifications.

The good sintering regime achieved at the high sintering temperatures is also concluded by looking at the values of the Vickers microhardness. However, a small decay of the hardness is observed in the samples sintered at $1300^{\circ} \mathrm{C}$. Statistically, the values of all groups (with respect to the sintering temperature) are significantly different among each other $(P>0.05)$.

Figures 3 and 4 present the major mechanical properties of the BCP samples, that is, modulus of elasticity, compression strength, and toughness. These plots suggest that the optimum sintering temperature is $1100^{\circ} \mathrm{C}$. On one hand, although results of modulus of elasticity and compression strength at 1000 and $1200^{\circ} \mathrm{C}$ are not significantly different $(P<0.05)$, those at 1100 and $1300^{\circ} \mathrm{C}$ are significantly different $(P=0.01)$. On the other hand, results of toughness at 1200 and $1300^{\circ} \mathrm{C}$ are not significantly different $(P<0.05)$.

For the $\mathrm{BCP}$ samples sintered at $1100^{\circ} \mathrm{C}$, the modulus of elasticity is evaluated as $37.11 \mathrm{GPa}$ (Figure 3), which is significantly higher that the values of TCP reported by Metsger et al. [5] and Wang et al. [8], which are 21 and 24.6 GPa, respectively. Additionally, in Figure 4, value of toughness in this work at $1100^{\circ} \mathrm{C}$ is $4.34 \mathrm{~J} / \mathrm{cm}^{3}$ (Figure 4), which is much higher than the value $2.34 \mathrm{~J} / \mathrm{cm}^{3}$ reported by Metsgeret al. [5].

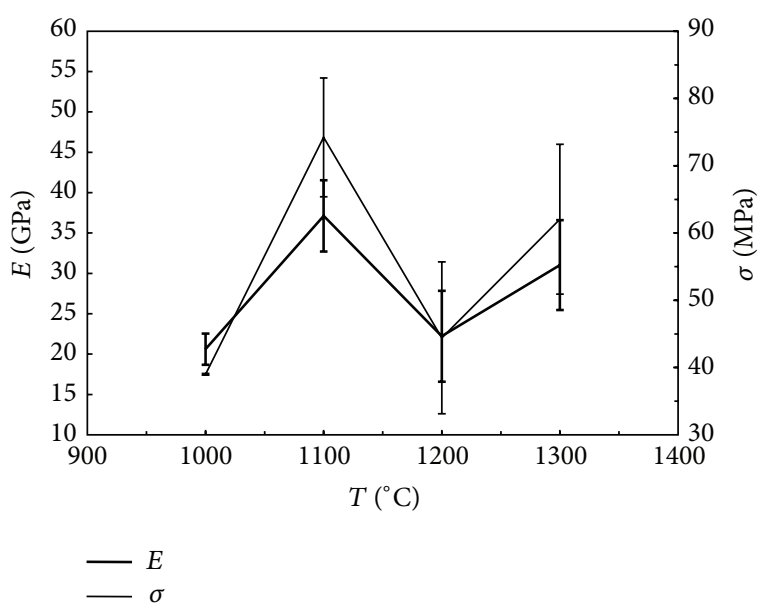

FIGURE 3: Influence of modulus of elasticity $(E)$ and compression strength $(\sigma)$ of the BCP ceramics on sintering temperature.

Also, one can find interesting similarities between the results of compression strength in the present study (Figure 3) and the results of flexural strength of HA $+11 \%$ TCP [4]; that is, the strength (whether compressive or flexural) increases 


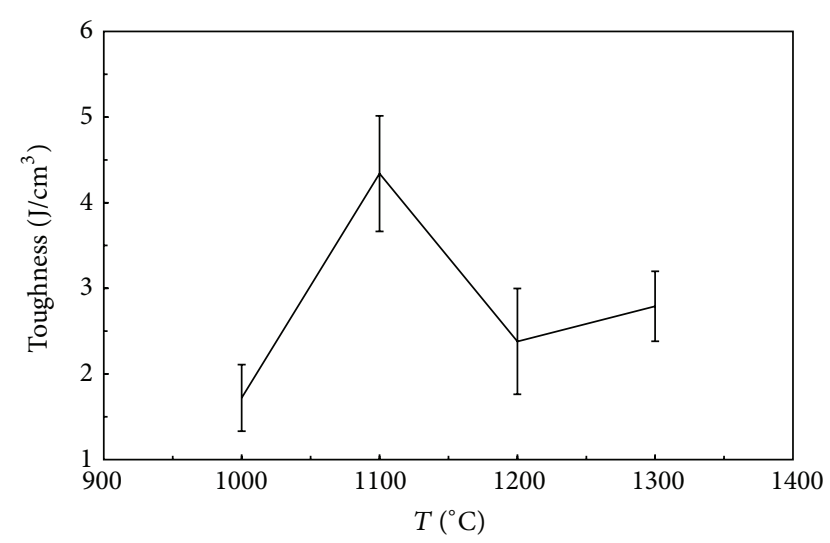

FIGURE 4: Influence of toughness of the BCP ceramics on sintering temperature.

up to $1100^{\circ}$, decreases at $1200^{\circ} \mathrm{C}$, and finally it again increases at $1300^{\circ} \mathrm{C}$.

A similar comparison can be easily done with the values of Vickers hardness from this work and the studies of [11, $13,15,16]$. The behavior of these mechanical properties with increasing sintering temperature does not follow the evolution of density values with increasing sintering temperature (Table 1) and, therefore, it can be attributed to the phase transformation of TCP between $\beta$ and $\alpha$ phase between $1100^{\circ} \mathrm{C}$ and $1200^{\circ} \mathrm{C}$.

As a specific comparison in the sintering temperature range of $1040-1100^{\circ} \mathrm{C}$, a graphical representation in [16] indicates that the modulus of elasticity and Vickers hardness of BCP (30\% HA and 70\% TCP) samples sintered at around $1045^{\circ} \mathrm{C}$ are 109 and $5.1 \mathrm{GPa}$, respectively. However, the present study shows that modulus of elasticity and Vickers hardness of BCP (30\% HA and 70\% TCP) samples sintered at $1100^{\circ} \mathrm{C}$ are 34 and $1.94 \mathrm{GPa}$, respectively.

\section{Conclusions}

The experimental results of this study, which agree fairly well with the results of earlier studies reported in the literature, suggest that the sintering behavior and the mechanical properties of the BCP-containing ceramics strongly depend on the sintering temperature. With regard to the consolidation, good sintering regime can be achieved at $1200^{\circ} \mathrm{C}$, which is reflected in the high values of density and the Vickers hardness as well as in the highly dense microstructure. However, the formation of inter- and intragranular cracks, observed in the samples sintered at $1200^{\circ} \mathrm{C}$, attributed to the transformation of $\beta$-TCP into $\alpha$-TCP, jeopardizes the good mechanical properties. This transformation phase of TCP should occur between $1100^{\circ} \mathrm{C}$ and $1200^{\circ} \mathrm{C}$. This transformation explains the influence of sintering temperature on the values of compressive strength, modulus of elasticity, and toughness, that is, the achievement of the best values at $1100^{\circ} \mathrm{C}$, the decay of these properties at $1200^{\circ} \mathrm{C}$, and their increase again at $1300^{\circ} \mathrm{C}$.
It can be also concluded that some results are different from those in the literature. In general, this may be caused by different sample preparation techniques. This study shows that a function of HA : TCP ratio sintering temperature is still being investigated for estimating the mechanical properties of the $\mathrm{BCP}$ ceramics with respect to the preparation techniques.

\section{Conflict of Interests}

The author declares that there is no conflict of interests regarding the publication of this paper.

\section{References}

[1] N. Kivrak and A. C. Taş, "Synthesis of calcium hydroxyapatitetricalcium phosphate (HA-TCP) composite bioceramic powders and their sintering behavior," Journal of the American Ceramic Society, vol. 81, no. 9, pp. 2245-2252, 1998.

[2] O. Brown, M. McAfee, S. Clarke, and F. Buchanan, "Sintering of biphasic calcium phosphates," Journal of Materials Science: Materials in Medicine, vol. 21, no. 8, pp. 2271-2279, 2010.

[3] S. V. Dorozhkin, "Biphasic, triphasic and multiphasic calcium orthophosphates," Acta Biomaterialia, vol. 8, no. 3, pp. 963-977, 2012.

[4] A. Royer, J. C. Viguie, M. Heughebaert, and J. C. Heughebaert, "Stoichiometry of hydroxyapatite: influence on the flexural strength," Journal of Materials Science: Materials in Medicine, vol. 4, no. 1, pp. 76-82, 1993.

[5] D. S. Metsger, M. R. Rieger, and D. W. Foreman, "Mechanical properties of sintered hydroxyapatite and tricalcium phosphate ceramic," Journal of Materials Science: Materials in Medicine, vol. 10, no. 1, pp. 9-17, 1999.

[6] D. K. Pattanayak, R. Dash, R. C. Prasad, B. T. Rao, and T. R. Rama Mohan, "Synthesis and sintered properties evaluation of calcium phosphate ceramics," Materials Science and Engineering C, vol. 27, no. 4, pp. 684-690, 2007.

[7] F. H. Perera, F. J. Martínez-Vázquez, P. Miranda, A. L. Ortiz, and A. Pajares, "Clarifying the effect of sintering conditions on the microstructure and mechanical properties of $\beta$-tricalcium phosphate," Ceramics International, vol. 36, no. 6, pp. 1929-1935, 2010.

[8] C. X. Wang, X. Zhou, and M. Wang, "Influence of sintering temperatures on hardness and Young's modulus of tricalcium phosphate bioceramic by nanoindentation technique," Materials Characterization, vol. 52, no. 4-5, pp. 301-307, 2004.

[9] S. Nakamura, R. Otsuka, H. Aoki, M. Akao, N. Miura, and T. Yamamoto, "Thermal expansion of hydroxyapatite- $\beta$ tricalcium phosphate ceramics," Thermochimica Acta, vol. 165, no. 1, pp. 57-72, 1990.

[10] S. Raynaud, E. Champion, J. P. Lafon, and D. BernacheAssollant, "Calcium phosphate apatites with variable $\mathrm{Ca} / \mathrm{P}$ atomic ratio III. Mechanical properties and degradation in solution of hot pressed ceramics," Biomaterials, vol. 23, no. 4, pp. 1081-1089, 2002.

[11] S.-F. Ou, S.-Y. Chiou, and K.-L. Ou, "Phase transformation on hydroxyapatite decomposition," Ceramics International, vol. 39, no. 4, pp. 3809-3816, 2013.

[12] R. Z. Legeros, S. Lin, R. Rohanizadeh, D. Mijares, and J. P. Legeros, "Biphasic calcium phosphate bioceramics: preparation, properties and applications," Journal of Materials Science: Materials in Medicine, vol. 14, no. 3, pp. 201-209, 2003. 
[13] R. Enderle, F. Götz-Neunhoeffer, M. Göbbels, F. A. Müller, and P. Greil, "Influence of magnesium doping on the phase transformation temperature of $\beta$-TCP ceramics examined by Rietveld refinement," Biomaterials, vol. 26, no. 17, pp. 3379-3384, 2005.

[14] E. Pecheva, P. Montgomery, D. Montaner, and L. Pramatarova, "White light scanning interferometry adapted for large-area optical analysis of thick and rough hydroxyapatite layers," Langmuir, vol. 23, no. 7, pp. 3912-3918, 2007.

[15] M. Descamps, L. Boilet, G. Moreau et al., "Processing and properties of biphasic calcium phosphates bioceramics obtained by pressureless sintering and hot isostatic pressing," Journal of the European Ceramic Society, vol. 33, no. 7, pp. 1263-1270, 2013.

[16] K.-T. Chu, S.-F. Ou, S.-Y. Chen, S.-Y. Chiou, H.-H. Chou, and K.-L. Ou, "Research of phase transformation induced biodegradable properties on hydroxyapatite and tricalcium phosphate based bioceramic," Ceramics International, vol. 39, no. 2, pp. 1455-1462, 2013. 

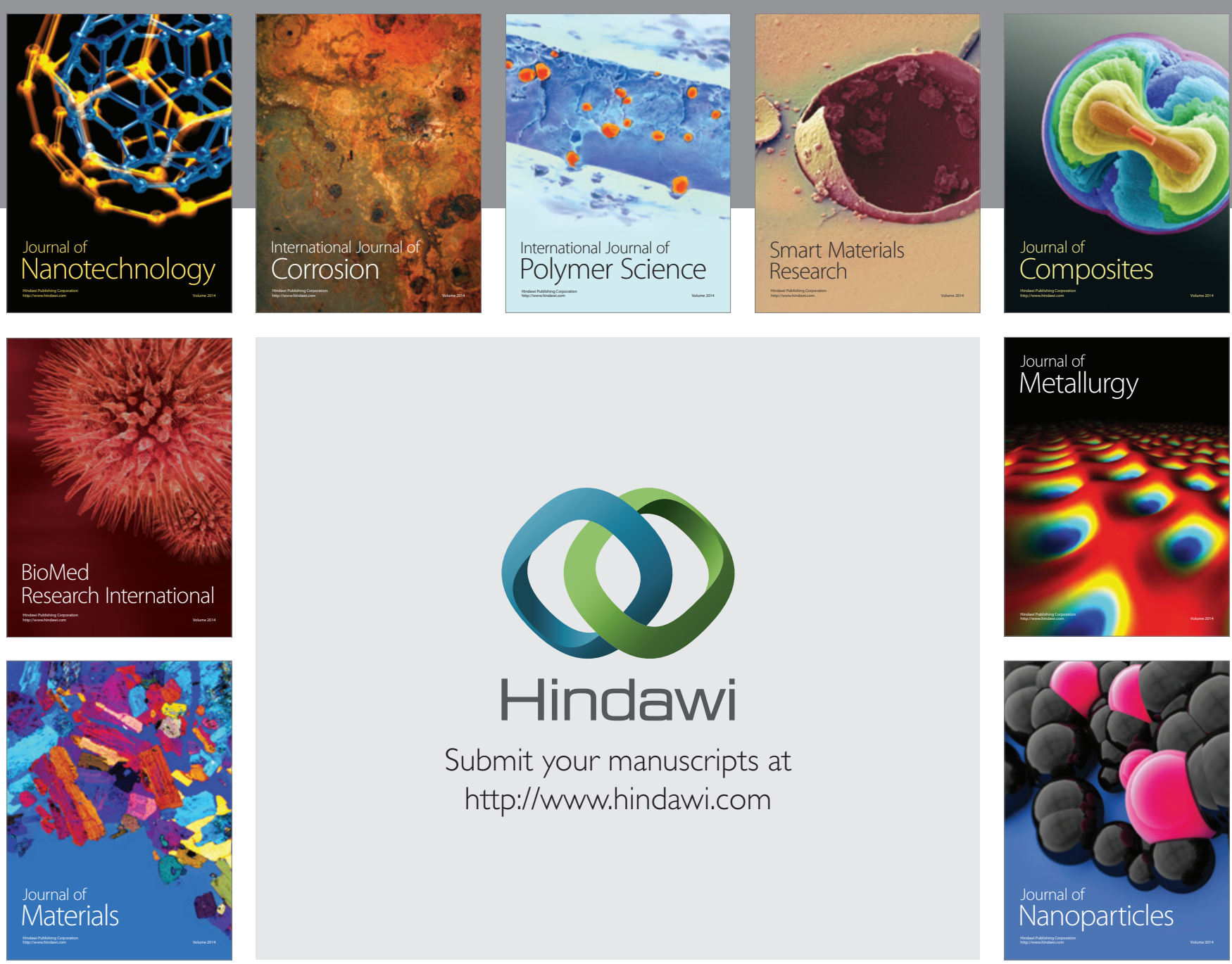

Submit your manuscripts at http://www.hindawi.com
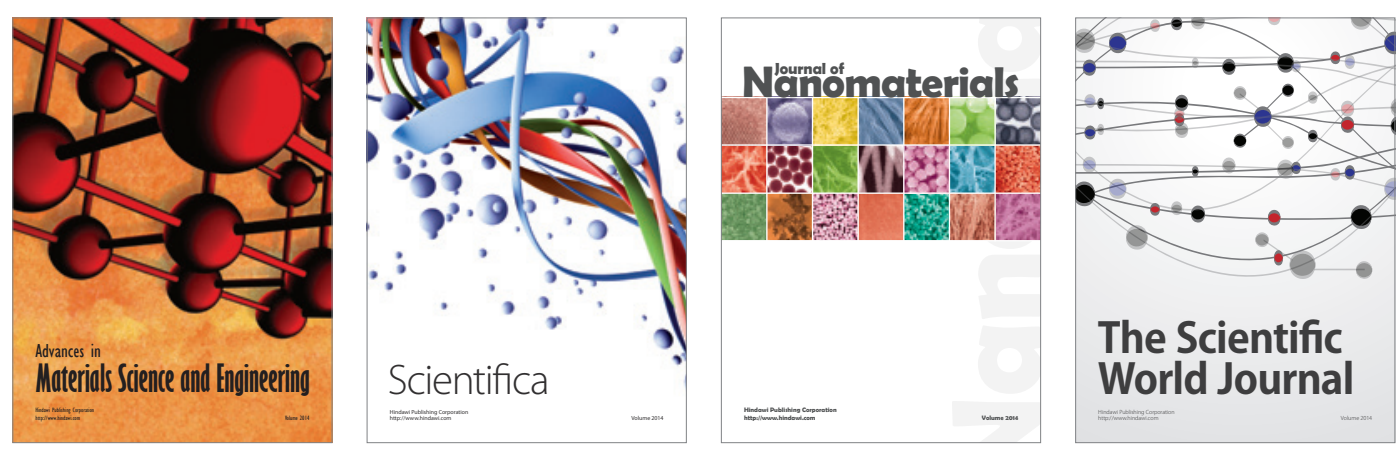

\section{The Scientific World Journal}
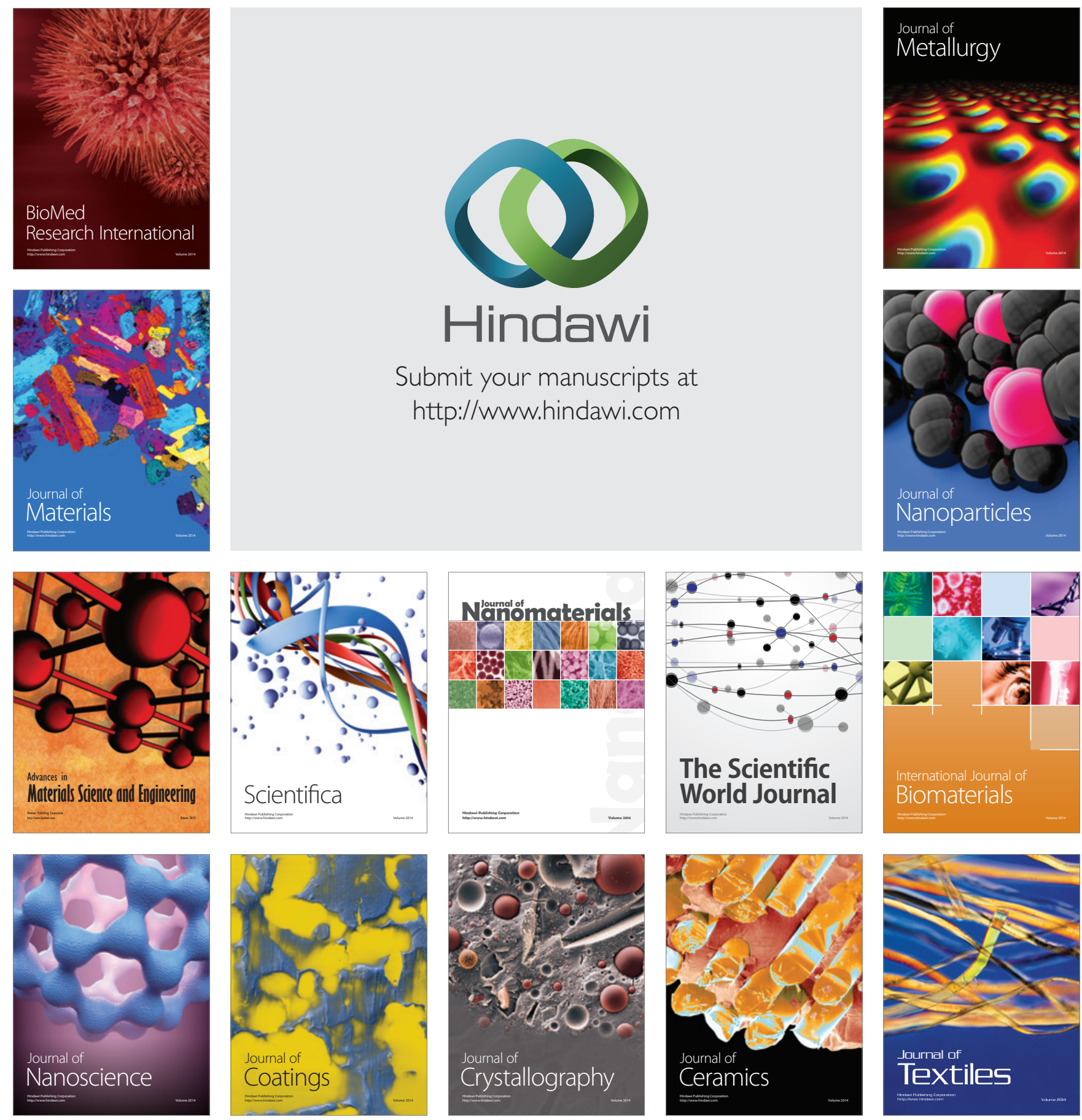